\title{
Tourism Satellite Account as a tool for enhancing labour market statistics in tourism industry (applied to tourism sector in Egypt)
}

\author{
Ahmad Muhammad Ragab ${ }^{1}$
}

Received: 29/07/2011

\footnotetext{
${ }^{1}$ Lecturer in the Faculty of Tourism \& Hotels, Minia University, Egypt, phone: 0020106256197 , e-mail: ahmadragab6666@yahoo.com

Supervisor: Prof. Dr. Mohammed Ibrahim Eraqi, Professor of Tourism Studies Department, Faculty of Tourism and Hotels, Fayoum University.

Dr. Ayman Mouneir Kasem, Assistant Professor in Tourism Studies Department, Faculty of Tourism and Hotels, Minia University.

Dr. Suzan Bakri Hassan, Assistant Professor in Tourism Studies Department, Faculty of Tourism and Hotels, Fayoum University
}

Institution awarding the Ph. D. Degree: Tourism Studies Department, Faculty of Tourism and Hotels, Fayoum University, Egypt.

Date of defence: $11^{\text {th }}$ October 2010

(C) 2011 International University College. All rights reserved

Citation: Ragab, A. M. (2011), Tourism Satellite Account as a tool for enhancing labour market statistics in tourism industry (applied to tourism sector in Egypt). Doctoral dissertation summary. European Journal of Tourism Research 4(2), pp. 233-236

\section{Goal and objectives of the dissertation Goal}

The goal of the study is to develop a comprehensive Tourism Human Resource Module of the Tourism Satellite Accounts (TSAHRM) which can complement and enhance the analytical capacity provided by the Tourism Satellite Accounts (TSA), allowing for a broader insight into tourism's role in the economy, especially in the Egyptian economy.

\section{Objectives}

The objectives of the study are:

1. Evaluating the current situation of tourismrelated employment statistics and information in Egypt.
2. Formulate a TSA-HRM framework for measuring the various aspects, monetary and qualitative, of tourism human resources in the Egyptian economy environment with consistency with World Tourism Organisation (UNWTO) standards of the TSA.

\section{Methodology}

In general, this study depends on primary and secondary data to reach its findings and suggest a framework to capture the human resources aspects related to the tourism sector in the Egyptian economy. The research approach for the study is a case study that allows the empirical testing of the anticipated framework on a national statistical system. 

sector in Egypt). Doctoral dissertation summary.

Egypt was selected as the case study for this research.

One of the methods of supporting the case study approach is through the analysis of secondary data from existing statistical sources to determine the gaps between underlying concepts and existing data against those internationally proposed.

This study has relied on The Data Quality Assessment Framework (DQAF) introduced by the International Monetary Fund (IMF) for assessing the quality of existing data about TSA and tourism employment in Egypt. The IMF DQAF identifies quality-related features of governance of statistical systems, statistical processes, and statistical products. It addresses a broad range of questions that are captured through the prerequisites of quality and five dimensions of quality: assurances of integrity, methodological soundness, accuracy and reliability, serviceability, and accessibility.

As indicated above, one of the major objectives of this study is to identify the current situation of the data on tourism-related employment available in Egypt now and the quality level of the TSA data in Egypt. These additional data required (over and above the secondary sources of data) are gathered through the participant observation method.

\section{Results}

The results begin by assessing the current situation of the data on tourism-related employment available in Egypt now. This is followed by a quality assessment of the TSA project in context of the DQAF criteria.

Firstly, the study has drawn a whole picture of tourism-related employment available in Egypt now which can be described as following:

1. Broadly, although the great economic role that tourism sector plays in the Egyptian economy, the present available tourism statistics and data do not display the actual contribution of this sector. This is due to the present tourism statistical system which confronts several shortcomings and problems;

2. Statistics on tourism-related employment in Egypt is usually fragmented, difficult to compare and often lacks quality, credibility and reliability;

3. Considering the inadequate status of tourism employment statistics in Egypt, there is still much to be done to improve the quality of Egypt's tourism employment statistics;

4. TSA implementation in Egypt will create a new horizon for improving the quality of tourism employment statistics.

Secondly, the following represent the overall findings of the assessment of TSA Data quality in Egypt:

1. The TSA unit and the agencies that cooperate with them work within a satisfactory legal and institutional framework that supports the statistical work.

2. The TSA unit displays an awareness of quality as the cornerstone of statistical work.

3. Staff resources are insufficient for producing statistics.

4. The TSA unit displays professionalism and is aiming for transparency in their statistical practices.

5. TSA methodology is, to a large extent, consistent with the UNWTO recommendations.

6. TSA experience in Egypt is in need of more involvement of the private sector (hotels, restaurants, travel agents, guides, etc.) as it is data sources and end users of TSA results.

7. As for the tourism employment data, produced by the TSA unit, there are no classifications for occupation, status in employment, level of education, etc.

8. The level of details in tourism employment surveys carried out by the TSA unit allows for these data to be linked to international standard classifications.

\section{Theoretical conclusions}

In spite of the importance of providing data on tourism-related employment in Egypt, they are usually fragmented, difficult to compare and often lacks quality. Different methods and different sources often result in different figures, confusing the end-users. Therefore, most data on tourism-related employment in Egypt lacks credibility and comparability. On the other hand, the recommended framework for TSA is mainly in monetary terms. Table 7 in the TSA (Employment in the tourism industries) is rather an exception as it includes physical 
units. The UNWTO states that this table is insufficient for many purposes of social and economic policy making. In view of that, there is an inevitable necessity to develop a comprehensive framework to analyze the tourism human resources characteristics in Egypt, complying with the same underlying concepts mentioned in the Tourism Satellite Accounts (TSA).

In the same context, the TSA unit in Egypt is sparing no efforts to improve tourism statistics needed for developing and monitoring tourism policies. There is a general awareness of the need for good quality data for these purposes. Thus, the results of the TSA will be accurate, comparable and reliable for constructing the proposed TSA-HRM. Besides, the survey of tourism employment carried out by the TSA unit in 2009 will be a major data source for the proposed model of this study, but after some adjustments and additional elements to make it in line with the structure of the proposed module.

\section{Practical application of the dissertation}

Based on the research findings, the study has developed a Human Resources Module on the basis of the Tourism Satellite Account to extend the analytical capacity of the TSA as well as trace most issues that relevant to the tourism labour market in Egypt.

The study has covered the following issues as the components of the proposed TSA-HRM:

- The Accounting framework

- The Concepts and definitions

- The Classifications

- The Data sources

- The Methodology

- The structure of the proposed TSA-HRM

\section{Content of the dissertation}

\section{Abstract of chapter one (Literature Review)}

The primary purpose of this study is to formulate a framework for analyzing tourism labour market on the basis of the TSA. In continuity of the research process, the purpose of this chapter has been to review appropriate literature to identify key questions that need to be posed in the process of developing the proposed framework. Given that, it is necessary to obtain insights into the TSA's definitions and methodology, tourism labour market characteristics, employment area in the TSA, experiences in devolving employment modules, and finally the conceptual accounting of the TLAS. Undoubtedly these areas will be considered in the structure of the proposed TSA-HRM in Egypt as being discussed in the following chapters.

\section{Abstract of chapter two (Study Methodology)}

In this study, one strategy and one method associated with the qualitative approach are used. This chapter explains the strategy which refers to the case study and the method, which refers to Participant observation. Moreover, because of the exploratory characteristic of this study, the research is based on both primary data and secondary data. On the other hand, in-depth analyses of TSA project in Egypt are performed using the DQAF framework. The following chapter is dedicated on describing Tourism and employment statistics in Egypt as it is the case study chosen for this research.

\section{Abstract of chapter three (The Case of Egypt)}

This chapter discusses the case of Egypt considering that the present available statistics and data do not display the actual contribution of tourism sector, even though, the great economic role that tourism plays in the Egyptian economy. This is due to the present statistical system confronts several shortcomings and problems.

\section{Abstract of chapter four (Discussion and Results)}

This chapter presents findings for the study questions through the result of the assessment of the TSA project in Egypt according to the generic DQAF dimensions. Besides, the secondary information comprising of MOT documents, published tourism statistics, annual reports of governmental organizations and recent studies related to tourism employment statistics in Egypt. The results indicate that statistics on tourism-related employment in Egypt is usually fragmented, difficult to compare and often lacks quality, credibility and reliability. On the other hand, TSA implementation in Egypt will create a new horizon for improving the quality of tourism 

sector in Egypt). Doctoral dissertation summary.

employment statistics. In the same context, the process of TSA project in Egypt assessment generally, shows that Egypt has a good experience in implementing the TSA system. Therefore, the application of the TSA in Egypt at this high level is considered as a starting point and an important source for developing a special framework of tourism employment statistics in Egypt.

Abstract of chapter five (Conclusion and the Proposed TSA-HRM)

In this chapter the author suggests a TSA-HRM on the basis of the TSA and according to the tourism business environment in Egypt. This chapter deals with all aspects of the proposed model. Besides, the author develops the data collection tools needed for the proposed model. This chapter defines two proposed areas for future research:

1. Performing end-user needs assessment of Tourism employment statistics. Then, reviewing the proposed module according to this assessment;

2. Conducting the proposed tools of the TSAHRM on a small sample of core tourism characteristic industries in Egypt to examine this module. According to the findings of that survey, a review of the proposed Module could be done. 